\title{
STABILISING SELECTION IN CONSTANT AND FLUCTUATING ENVIRONMENTS
}

\author{
JOHN B. GIBSON and BRIAN P. BRADLEY* \\ Department of Genetics, University of Cambridge
}

Received 16.vii.73

\begin{abstract}
Summary
Selection in both constant and fluctuating temperature environments for a constant bristle number in Drosophila melanogaster resulted in the maintenance of that number and in a decrease of both genetic and environmental variance. Although mean bristle number in the control lines increased over the early generations there was a significant net decrease. Phenotypic variance decreased significantly, especially in later generations. In both control lines and in the line selected at $20-29^{\circ} \mathrm{C}$. there was a significant decrease in asymmetry of bristle number. There was also a decrease in environmental variance in these three lines. Transplant experiments showed that when the lines were cultured in alien environments phenotypic variance tended to increase in the fluctuating and decrease in the constant temperature environment. However at generation 39, the phenotypic variance of lines selected in the fluctuating environment increased when samples of the lines were cultured in the constant temperature environment. The results indicate that stabilising selection can be effective in both fluctuating and constant temperature environments.
\end{abstract}

\section{INTRODUGTION}

NATURAL selection is thought to be mainly conservative. Its consequences are more often maintenance of the status quo than systematic changes in gene frequencies. There is evidence that the modal phenotypes in a population have the highest reproductive fitness (Rendel, 1943; Karn and Penrose, 1951; Jayant, 1966). The optimum phenotype itself changes with shifts in gene frequency or in the environment and it is assumed that the modal phenotype is a result of natural selection.

In a population inhabiting a relatively stable environment, the fittest genotypes would be those tending to produce intermediate phenotypes. When the fitness of a phenotype decreases with its deviation from the modal phenotypes, selection is said to be stabilising. Such selection has been investigated theoretically (Wright, 1935; Robertson, 1956; Latter, 1960; Curnow, 1964; Singh and Lewontin, 1966; Gale and Kearsey, 1968) and experimentally (Falconer, 1957; Thoday, 1959; Prout, 1962; Scharloo, 1964; Barnes, 1968). All of these studies assumed or were carried out in a constant environment.

The present experiments were started with the view of seeing whether stabilising selection in an environment with marked fluctuations in temperature could bring about a reduction in additive genetic variance and whether natural selection under the same conditions would have similar effects.

* Present address: Biological Sciences, University of Maryland Baltimore County, Catonsville, Maryland 21228. 


\section{METHodS}

Flies from the second generation progeny of a Drosophila melanogaster female taken on an apple dump near Cambridge were used to set up four bottle cultures in both a constant $25^{\circ} \mathrm{C}$. incubator and in a fluctuating incubator in which the temperature was $29^{\circ} \mathrm{C}$. for 12 hours followed by $20^{\circ} \mathrm{C}$. for 12 hours. The time required to change from one temperature to the other in the fluctuating incubator was about half an hour.

Twenty virgin flies of each sex from each of the four cultures at $25^{\circ} \mathrm{C}$. were assayed for sternopleural bristle number. Sixteen males and 16 females were taken at random from the combined progenies to set up four control line cultures at $25^{\circ} \mathrm{C}$. each with four pairs of parents. The 16 males and 16 females nearest the mean bristle number (17 for females, 16 for males) were selected from the remaining flies and used as parents for the four cultures of the stabilising selection lines maintained at $25^{\circ} \mathrm{C}$. In subsequent generations 20 flies of each sexwere assayed from each of the four cultures in a line. The parents of the next generation were selected from the combined progeny for the stabilised lines and taken at random for the control lines. The lines cultured in the fluctuating environment were established and maintained in a similar way except that in the selected line females with 18 bristles and males with 17 bristles were selected as there was a significant difference in mean bristle number between the flies cultured in the two environments (see below).

Changes in additive genetic variance were estimated by heritability tests in the base population and in all the lines at generations $S_{11}, S_{19}$ and $S_{39}$. At these generations replicate samples of all the lines were grown in both the fluctuating and constant temperature environments to provide estimates of phenotypic variance in the two environments and to provide parents for the heritability tests. In the heritability tests single-pair matings were set up in which the parents were positively assortatively mated for bristle number and their progenies grown in the same temperature environment as the parents. Five flies of each sex were assayed from the progeny of each pair of flies and the regression of offspring mean bristle number on mid-parent mean was calculated.

\section{Results}

\section{(i) The base population}

At the time the selection and control lines were initiated replicate samples of the base population were cultured at $25^{\circ} \mathrm{C}$. and in the fluctuating temperature environment. From the progenies heritability tests were set up in

TABLE 1

Base population. Heritability tests in both constant and fluctuating environments

$$
\begin{array}{ll}
20^{\circ} \mathrm{C} .-29^{\circ} \mathrm{C} . & b=0.35 \pm 0.084 \\
25^{\circ} \mathrm{C} . & b=0.59 \pm 0.077
\end{array}
$$

Analysis of variance

\begin{tabular}{lccc}
\multicolumn{1}{c}{ Source } & d.f. & Mean square & Probability \\
Joint regression & 1 & 8828.4 & $<0.001$ \\
Difference between regressions & 1 & $5961 \cdot 1$ & $<0.001$ \\
Difference between means & 1 & 9281.3 & $<0.001$ \\
Error & 55 & 137.9 & -
\end{tabular}


TABLE 2

Components of variance on the base population cultured in both constant and fluctuating environments

$\begin{array}{cccc}\text { Temperature } & \text { VP } & \text { VA } & \text { VE } \\ 25^{\circ} \mathrm{C} . & 4 \cdot 2 & 2 \cdot 5 & 1.7 \\ 20^{\circ} \mathrm{C} .-29^{\circ} \mathrm{C} \text {. } & 6 \cdot 2 & 2 \cdot 2 & 4.0\end{array}$

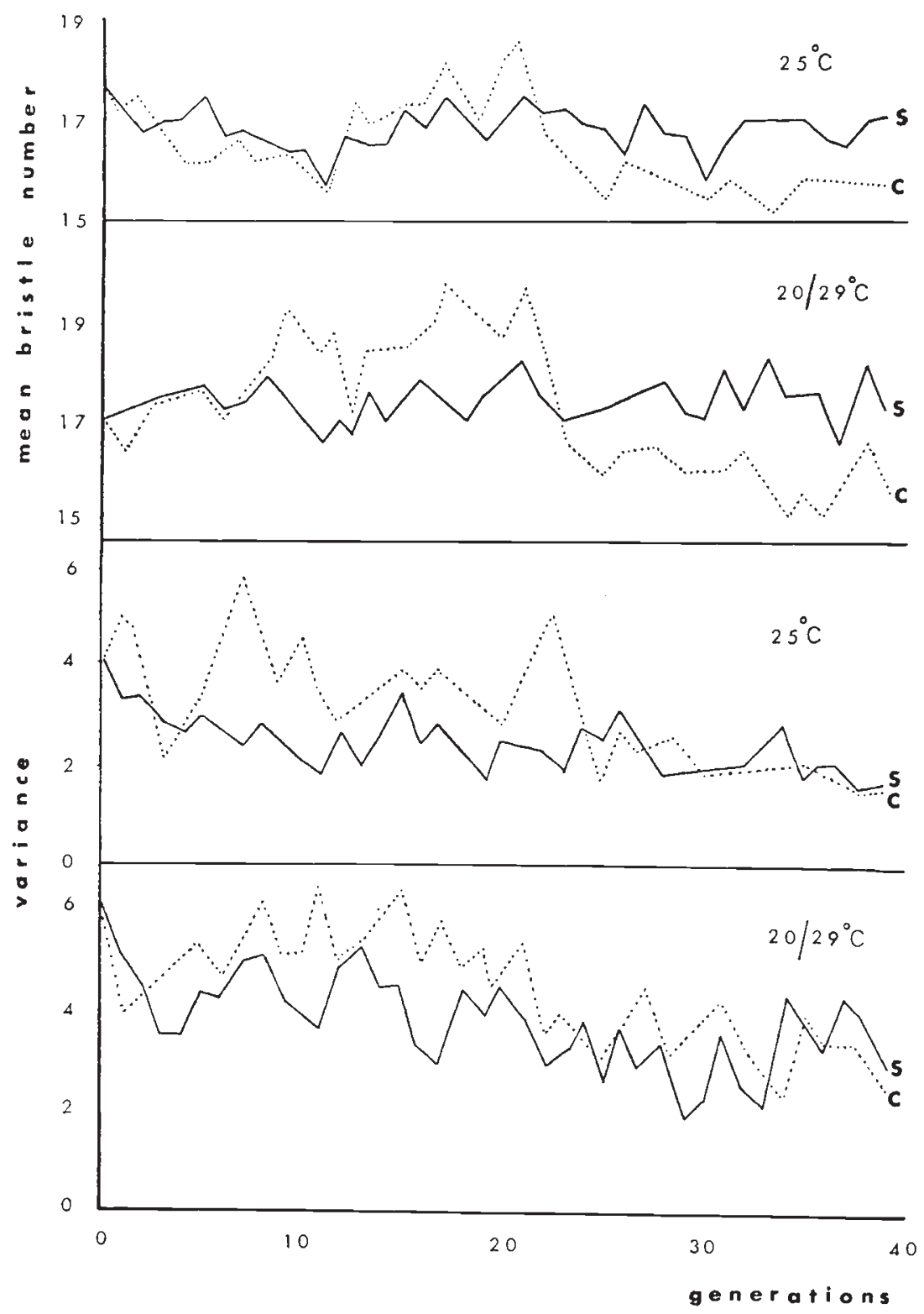

FIG. 1.-Mean bristle number and variance in the control $(C)$ and selected $(S)$ lines. 
the two environments. The regressions of progeny mean bristle number on mid-parent mean in the two environments were significantly different (table 1). The heritability estimates were used to partition the phenotypic variance in the samples of the base population cultured in the two environments (table 2). As might have been expected, phenotypic variance was higher in the fluctuating temperature environment than in the constant environment and this difference was largely due to the higher environmental and/or non-additive genetic variance in the fluctuating environment.

(ii) Generations $S_{1}$ to $S_{19}$

As heritability tests were carried out at $S_{19}$ it is useful to consider first changes in mean bristle number and variance (within sex and culture) which occurred in the lines over these early generations (fig. 1). The regression of mean bristle number in the $25^{\circ} \mathrm{C}$. stabilised line on generation

TABLE 3

Regressions of mean bristle number and variance over the first nineteen generations of selection

\begin{tabular}{|c|c|c|c|c|}
\hline Character & Temperature & Line & Linear regression & $\begin{array}{l}\text { Probability } \\
\text { of difference } \\
\text { between } \\
\text { regressions }\end{array}$ \\
\hline Bristle number & $\begin{array}{l}25^{\circ} \mathrm{C} \text {. } \\
25^{\circ} \mathrm{C} \\
20-29^{\circ} \mathrm{C} \\
20-29^{\circ} \mathrm{C}\end{array}$ & $\begin{array}{l}\text { S } \\
\text { Control } \\
\text { S } \\
\text { Control }\end{array}$ & $\left.\begin{array}{r}-0.005 \pm 0.017 \\
0.048 \pm 0.025 \\
0.043 \pm 0.022 \\
0.128 \pm 0.020\end{array}\right\}$ & $\begin{array}{l}\text { N.S. } \\
<0.05\end{array}$ \\
\hline Variance & $\begin{array}{l}25^{\circ} \mathrm{C} \\
25^{\circ} \mathrm{C} \\
20-29^{\circ} \mathrm{C} \\
20-29^{\circ} \mathrm{C}\end{array}$ & $\begin{array}{l}\text { S } \\
\text { Control } \\
\mathrm{S} \\
\text { Control* }\end{array}$ & $\left.\begin{array}{r}-0.029 \pm 0.009 \\
-0.049 \pm 0.037 \\
-0.093 \pm 0.019 \\
0.057 \pm 0.025\end{array}\right\}$ & $\begin{array}{l}\text { N.S. } \\
<0.05\end{array}$ \\
\hline
\end{tabular}

was not significant whereas the regression of phenotypic variance on generation was negative and significant (table 3 ). The mean bristle number in the $25^{\circ} \mathrm{C}$. control line increased, but not significantly, and there was no significant change in phenotypic variance.

In the fluctuating environment the mean bristle number of the control line increased significantly while that of the stabilised line did not. Phenotypic variance had decreased significantly in the stabilised line but not in the control line in the fluctuating environment by generation 19 (table 3 ).

Comparison of regression coefficients in selected and control lines indicated significant difference in regressions of both mean and variance on generations in the fluctuating environment but of neither in the $25^{\circ} \mathrm{C}$. environment (table 3 ). There was only one significant deviation from linearity as shown by the addition of quadratic and higher terms to each regression equation.

Heritability estimates based on tests carried out at $\mathrm{S}_{19}$ (table 4) were used to partition phenotypic variance in the lines. These data (table 5) indicate that, compared to the controls, there was less additive genetic variance in both selected lines. Phenotypic variance in both $25^{\circ} \mathrm{C}$. control and selected lines increased when the lines were cultured in the fluctuating environment, but there was more additive genetic variance in the control lines than in the 
stabilised line. In contrast, phenotypic variance in both fluctuating temperature lines decreased when the lines were cultured at $25^{\circ} \mathrm{C}$.; the control line showed a decrease in additive genetic variance and the stabilised line a decrease in environmental variance. The difference in phenotypic variance between samples of the base population cultured in the two environments were earlier shown to be largely due to changes in environmental variance.

TABLE 4

Heritability tests at $S_{19}$

\begin{tabular}{cl}
$\begin{array}{cl}\text { Line } \\
\text { temperature }\end{array}$ & \multicolumn{1}{c}{ Line } \\
$20-29^{\circ} \mathrm{C}$. & $\mathrm{S}$ \\
& Control \\
& S \\
& Control \\
& \\
$25^{\circ} \mathrm{C}$. & $\mathrm{S}$ \\
& Control \\
& S \\
& Control
\end{tabular}

$\begin{array}{cc}\begin{array}{c}\text { Culture temperature } \\ \text { of test }\end{array} & \text { Heritability } \\ 20-29^{\circ} \mathrm{C} . & 0 \cdot 32 \pm 0 \cdot 12 \\ 20-29^{\circ} \mathrm{C} . & 0 \cdot 62 \pm 0 \cdot 17 \\ 25^{\circ} \mathrm{C} . & 0 \cdot 45 \pm 0 \cdot 12 \\ 25^{\circ} \mathrm{C} . & 0 \cdot 38 \pm 0 \cdot 10 \\ & \\ 25^{\circ} \mathrm{C} . & 0 \cdot 46 \pm 0 \cdot 17 \\ 25^{\circ} \mathrm{C} & 0 \cdot 84 \pm 0 \cdot 20 \\ 20-29^{\circ} \mathrm{C} . & 0 \cdot 62 \pm 0 \cdot 17 \\ 20-29^{\circ} \mathrm{C} . & 0 \cdot 72 \pm 0 \cdot 18\end{array}$

These data suggest that during the first 19 generations artificial stabilising selection was more effective in reducing additive genetic variance than any natural stabilising selection that the control lines might have been subjected to. There is evidence that environmental variance was reduced in the control lines. The apparent effectiveness of artificial selection is corroborated by the heritability tests at $S_{11}$, where the variance components in the selected lines were intermediate between the estimates for $S_{0}$ and $S_{19}$. In the control lines the only clear trend is a reduction in environmental variance.

TABLE 5

Components of variance in the lines at $S_{19}$

\begin{tabular}{|c|c|c|c|c|c|c|c|}
\hline \multirow[b]{3}{*}{ Temperature } & \multirow[b]{3}{*}{ Line } & \multicolumn{6}{|c|}{ Culture temperature of test } \\
\hline & & \multicolumn{3}{|c|}{$20 / 29^{\circ} \mathrm{C}$} & \multicolumn{3}{|c|}{$25^{\circ} \mathrm{C}$. } \\
\hline & & VP & VA & VE & VP & VA & VE \\
\hline $20-29^{\circ} \mathrm{C}$ & $\begin{array}{l}\text { S } \\
\text { Control }\end{array}$ & $\begin{array}{l}3.9 \\
4.9\end{array}$ & $\begin{array}{l}1 \cdot 3 \\
3 \cdot 0\end{array}$ & $\begin{array}{l}2.6 \\
1.9\end{array}$ & $\begin{array}{l}3 \cdot 2 \\
3 \cdot 4\end{array}$ & $\begin{array}{l}1.4 \\
1.3\end{array}$ & $\begin{array}{l}1.8 \\
2.1\end{array}$ \\
\hline $25^{\circ} \mathrm{C}$. & & $3 \cdot 9$ & $2 \cdot 4$ & 1.5 & $1 \cdot 9$ & 0.9 & $1 \cdot 0$ \\
\hline & Control & $4 \cdot 5$ & $3 \cdot 2$ & $1 \cdot 3$ & $3 \cdot 1$ & $2 \cdot 6$ & 0.5 \\
\hline
\end{tabular}

(iii) Generations $S_{19}$ to $S_{39}$

The selection regime was continued for a further 20 generations after generation $\mathrm{S}_{19}$. Mean bristle number decreased significantly in both control lines over the 39 generations in contrast to the increase in bristle number in these lines over the first 19 generations. The quadratic terms in the regression equations for the means of both control lines are significant.

The regressions of mean bristle number on generations were not significant in either of the stabilised lines (table 6).

The regressions of variance (within sex and culture) for the 39 generations were negative and significant for the control and selected lines in both 
environments (table 6). Thus the change in phenotypic variance in both of the control lines occurred mainly over the last 20 generations (fig. 1). Only the regression of variance for the control line in the fluctuating environment was significantly non-linear.

Phenotypic variance in the four lines cultured in both environments was partitioned as before using heritability tests carried out at $S_{39}$ (tables 7 and 8).

\section{TABLE 6}

Regression of mean bristle number and variance over 39 generations

\begin{tabular}{|c|c|c|c|c|}
\hline Character & Temperature & Line & $\begin{array}{l}\text { Linear } \\
\text { regression }\end{array}$ & $\begin{array}{l}\text { Probability } \\
\text { of difference } \\
\text { between } \\
\text { regressions }\end{array}$ \\
\hline $\begin{array}{l}\text { Mean bristle } \\
\text { number }\end{array}$ & $\begin{array}{l}25^{\circ} \mathrm{C} \text {. } \\
25^{\circ} \mathrm{C} \text {. } \\
20-29^{\circ} \mathrm{C} \text {. } \\
20-20^{\circ} \mathrm{C}\end{array}$ & $\begin{array}{l}\text { S } \\
\text { Control* } \\
\text { S } \\
\text { Control* }\end{array}$ & $\left.\begin{array}{l}-0.003 \pm 0.041 \\
-0.031 \pm 0.012 \\
+0.005 \pm 0.044 \\
-0.074 \pm 0.016\end{array}\right\}$ & $\begin{array}{l}<0.05 \\
<0.05\end{array}$ \\
\hline Variance & $\begin{array}{l}25^{\circ} \mathrm{C} \text {. } \\
25^{\circ} \mathrm{C} \text {. } \\
20-29^{\circ} \mathrm{C} . \\
20-29^{\circ} \mathrm{C} \text {. }\end{array}$ & $\begin{array}{l}\text { S } \\
\text { Control } \\
\text { S } \\
\text { Control* }\end{array}$ & $\left.\begin{array}{l}-0.022 \pm 0.006 \\
-0.081 \pm 0.015 \\
-0.031 \pm 0.012 \\
-0.065 \pm 0.012\end{array}\right\}$ & $\begin{array}{l}<0.05 \\
\text { N.S. }\end{array}$ \\
\hline
\end{tabular}

* Quadratic term in these equations negative and significant $(P<0.01)$.

TABLE 7

Heritability tests at $S_{30}$

\begin{tabular}{|c|c|c|c|}
\hline $\begin{array}{c}\text { Line } \\
\text { temperature }\end{array}$ & Line & $\begin{array}{c}\text { Culture } \\
\text { temperature } \\
\text { of test }\end{array}$ & Heritability \\
\hline \multirow{2}{*}{$20-29^{\circ} \mathrm{C}$} & $\begin{array}{l}\text { S } \\
\text { Control }\end{array}$ & $\begin{array}{l}20-29^{\circ} \mathrm{C} . \\
20-29^{\circ} \mathrm{C} .\end{array}$ & $\begin{array}{l}0.48 \pm 0.08 \\
0.35 \pm 0.06\end{array}$ \\
\hline & $\begin{array}{l}\text { S } \\
\text { Control }\end{array}$ & $\begin{array}{l}25^{\circ} \mathrm{C} . \\
25^{\circ} \mathrm{C} \text {. }\end{array}$ & $\begin{array}{l}0.35 \pm 0.09 \\
0.38 \pm 0.07\end{array}$ \\
\hline \multirow{2}{*}{$25^{\circ} \mathrm{C}$} & $\begin{array}{l}\text { S } \\
\text { Control }\end{array}$ & $\begin{array}{l}25^{\circ} \mathrm{C} . \\
25^{\circ} \mathrm{C} .\end{array}$ & $\begin{array}{l}0.28 \pm 0.08 \\
0.40 \pm 0.10\end{array}$ \\
\hline & $\begin{array}{l}\text { S } \\
\text { Control }\end{array}$ & $\begin{array}{l}20-29^{\circ} \mathrm{C} . \\
20-29^{\circ} \mathrm{C} .\end{array}$ & $\begin{array}{l}0.22 \pm 0.09 \\
0.25 \pm 0.12\end{array}$ \\
\hline
\end{tabular}

TABLE 8

Components of Variance at $S_{39}$

\begin{tabular}{|c|c|c|c|c|c|c|c|}
\hline \multirow[b]{3}{*}{ Temperature } & \multirow[b]{3}{*}{ Line } & \multicolumn{6}{|c|}{ Culture temperature of test } \\
\hline & & \multicolumn{3}{|c|}{$20-29^{\circ} \mathrm{C}$. } & \multicolumn{3}{|c|}{$25^{\circ} \mathrm{C}$} \\
\hline & & VP & VA & VE & VP & VA & VE \\
\hline $20-29^{\circ} \mathrm{C}$ & $\begin{array}{l}\text { S } \\
\text { Control }\end{array}$ & $\begin{array}{l}2 \cdot 7 \\
2 \cdot 6\end{array}$ & $\begin{array}{l}1 \cdot 3 \\
0.9\end{array}$ & $\begin{array}{l}1 \cdot 4 \\
1 \cdot 6\end{array}$ & $\begin{array}{l}5 \cdot 7 \\
3 \cdot 4\end{array}$ & $\begin{array}{l}2.0 \\
1.3\end{array}$ & $\begin{array}{l}3 \cdot 7 \\
2 \cdot 1\end{array}$ \\
\hline $25^{\circ} \mathrm{C}$ & $\begin{array}{l}\text { S } \\
\text { Control }\end{array}$ & $\begin{array}{l}4 \cdot 1 \\
3 \cdot 2\end{array}$ & $\begin{array}{l}0.9 \\
0.8\end{array}$ & $\begin{array}{l}3 \cdot 2 \\
2 \cdot 4\end{array}$ & $\begin{array}{l}2.1 \\
1.5\end{array}$ & $\begin{array}{l}0.6 \\
0.6\end{array}$ & $\begin{array}{l}1.5 \\
0.9\end{array}$ \\
\hline
\end{tabular}


The results are in marked contrast to those obtained at $\mathrm{S}_{19}$. The $25^{\circ} \mathrm{C}$. control line had a similar amount of additive genetic variance but less environmental variance than the $25^{\circ} \mathrm{C}$. stabilised line when the lines were cultured in either environment, although phenotypic variance was higher in the foreign environment. The control line in the fluctuating temperature environment had less additive genetic variance than the stabilised line but a similar amount of environmental variance. When these two lines were cultured in the constant $25^{\circ} \mathrm{C}$. environment phenotypic variance increased and there was more additive genetic variance and environmental variance in the stabilised line than in the control. The data in tables 2 to 8 on the components of variance are summarised in table 9.

TABLE 9

Summary of components of variance at $S_{0}, S_{19}$ and $S_{39}$

\begin{tabular}{|c|c|c|c|}
\hline \multirow[b]{2}{*}{ Generation } & \multirow[b]{2}{*}{ Line } & \multicolumn{2}{|c|}{ Line temperature } \\
\hline & & $\begin{array}{l}20-29^{\circ} \mathrm{C} . \\
\mathrm{VA}+\mathrm{VE}\end{array}$ & $\begin{array}{c}25^{\circ} \mathrm{C} . \\
\mathrm{VA}+\mathrm{VE}\end{array}$ \\
\hline$S_{0}$ & $\begin{array}{l}\text { Base } \\
\quad \text { population }\end{array}$ & $2 \cdot 2+4 \cdot 0$ & $2 \cdot 5+1 \cdot 7$ \\
\hline \multirow{2}{*}{$S_{19}$} & $\int \mathrm{C}$ & $\begin{array}{c}3 \cdot 0+1 \cdot 9 \\
(1 \cdot 3+2 \cdot 1)\end{array}$ & $\begin{array}{c}2 \cdot 6+0 \cdot 5 \\
(3 \cdot 2+1 \cdot 3)\end{array}$ \\
\hline & $\mathrm{S}$ & $\begin{array}{c}1 \cdot 3+2 \cdot 6 \\
(1 \cdot 4+1 \cdot 8)\end{array}$ & $\begin{array}{c}0 \cdot 9+1 \cdot 0 \\
(2 \cdot 4+1 \cdot 5)\end{array}$ \\
\hline \multirow{2}{*}{$S_{39}$} & $\int \mathrm{C}$ & $\begin{array}{c}0 \cdot 9+1 \cdot 6 \\
(1 \cdot 3+2 \cdot 1)\end{array}$ & $\begin{array}{c}0 \cdot 6+0 \cdot 9 \\
(0 \cdot 8+2 \cdot 4)\end{array}$ \\
\hline & $\mathrm{S}$ & $\begin{array}{c}1 \cdot 3+1 \cdot 4 \\
(2 \cdot 0+3 \cdot 7)\end{array}$ & $\begin{array}{c}0 \cdot 6+1 \cdot 5 \\
(0 \cdot 9+3 \cdot 2)\end{array}$ \\
\hline
\end{tabular}

Variances in brackets were obtained in the alien environment.

Analyses of variance were performed for each line in each generation, including culture and sex as independent variables and mean and variance of bristle number as dependents. No clear trend was observed in the proportion of total variance explained by culture differences. However, between-cultures variance was only rarely significant from generation 23 onwards, having been significant in at least two lines in every generation except one prior to that time.

Analyses of variance including line showed inter-line variance to be significant in 10 of the first 19 generations and in 15 of the last 20.

Thus the downward trend in variance observed within sex and culture is repeated in the variance between cultures (within lines), presumably largely environmental in origin. This reduction in inter-culture variance is partly responsible for the line differences observed in later generations.

\section{Discussion}

Of particular interest in the present experiments are the comparisons between the responses of the stabilised and control lines that occurred over the first 19 generations of selection and those that occurred later. Phenotypic variance decreased steadily over the 39 generations in both stabilised 
lines but the mean bristle numbers of these lines did not change significantly. In contrast, the mean bristle numbers of both control lines increased between $\mathrm{S}_{0}$ and $\mathrm{S}_{19}$, although over 39 generations there was a significant decrease in mean bristle number. Phenotypic variance showed little change in either of the control lines over the early generations but then it decreased significantly to values slightly lower than those in the stabilised lines.

These data suggest that up to $\mathrm{S}_{19}$ artificial stabilising selection was more effective in both the constant and fluctuating temperature environments than any natural stabilising selection that the control lines might have been subjected to. Heritability tests at $\mathrm{S}_{19}$ provided consonant results, for there was less additive genetic variance in both stabilised lines than in the control lines. Thereafter all of the lines show evidence of effective stabilising selection, although the optimum phenotype was probably lower in the control lines than the phenotype artificially selected in the stabilised lines. Barnes (1968) showed that sternopleural bristle number was subjected to stabilising selection in cage populations maintained at two temperatures, the optimum phenotype depending on the temperature. Evidence for the adaptive significance of sternopleural bristle number in populations maintained at different temperatures was previously obtained by Beardmore (in Thoday, 1959). However, it is not obvious why the mean bristle number in both of the present control lines first increased and then decreased. In fact, the sudden decrease in mean bristle number (and to a lesser extent the decrease in variance) which occurred in both control lines around $\mathbf{S}_{23}$ accounts for most of the changes over the last 19 generations. This sudden decrease does not seem to be related to changes in either temperature or relative humidity, both of which were recorded and show no marked variation during this period. In any case the sudden decrease in mean did not occur in the stabilised lines cultured in the same incubator. The population size in the control line at $25^{\circ} \mathrm{C}$. did fall 20 per cent. below that required for a complete assay and the deficiency of progeny in this line persisted for several generations. However, there was no such deficiency in numbers in the control line in the fluctuating environment. The reduction in mean observed around $\mathrm{S}_{23}$ occurred in all four cultures in both control lines.

Inbreeding cannot be excluded as a relevant factor in the changes described in any of these lines (Robertson, 1952, 1956). But it seems unlikely to be the sole factor as neither of the control lines showed the increase in phenotypic variance which frequently accompanies inbreeding when quantitative characters are scored (Reeve and Robertson, 1953). Each of the four cultures of each line was maintained by four pairs of parents to minimise inbreeding effects.

The base population of the present experiments had been maintained at $25^{\circ} \mathrm{C}$. in the laboratory for only two generations prior to the start of the experiments. Of course, the environmental conditions to which the natural population was adapted are unknown, but they are unlikely to have included constant temperature. In the transplant tests carried out at $\mathrm{S}_{19}$ phenotypic variance in both the fluctuating temperature lines decreased when these lines were cultured at $25^{\circ} \mathrm{C}$. However, in similar tests at $\mathrm{S}_{39}$ the phenotypic variance increased when the lines were cultured at $25^{\circ} \mathrm{C}$. That this increase in phenotypic variance resulted from developmentally unstable genotypes at $25^{\circ} \mathrm{C}$. is suggested by comparisons of asymmetry of bristle number of flies cultured in the two environments. 
Asymmetry, measured as the unsigned difference between the sides of the flies divided by total bristle number (A/T, see Thoday, 1958) was lower in flies cultured in the fluctuating environment than in flies cultured in the foreign $25^{\circ} \mathrm{C}$. environment at $\mathrm{S}_{39}$. This difference in asymmetry in the two environments was not apparent in the tests carried out on these two lines at $\mathrm{S}_{19}$. Thus is seems likely that adaptation to the fluctuating temperature conditions resulted in a loss of flexibility to adjust to a more constant temperature. Over the 39 generations of selection, mean asymmetry did not change significantly in the line selected at $25^{\circ} \mathrm{C}$. In the two control lines and in the line selected at $20-29^{\circ} \mathrm{C}$. there was a significant linear reduction in asymmetry.

The decreases in phenotypic variance which occurred in all four lines were not solely due to changes in additive genetic variance. Compared to the base population, environmental variance was less at $S_{39}$ in both selected and control lines in the fluctuating environment and it was also less in the $25^{\circ} \mathrm{C}$. control line.

Not all experiments with artificial stabilising selection result in decreased phenotypic variance, for Falconer (1957) reported little effect from selection of intermediate sternopleural bristle numbers in Drosophila melanogaster. The present results, however, are consonant with those of Thoday (1959), Prout (1962) and Scharloo (1964) in showing that artificial stabilising selection can bring about a reduction in phenotypic variance. The results differ from those of Prout and Thoday in that the reduction in some lines was not only in additive genetic variance but also in environmental variance.

In addition, the present experiments indicate that stabilising selection could be effective in the fluctuating environment that natural populations of Drosophila are more likely to be subjected to than the constant temperature conditions usually employed in laboratory experiments.

Acknowledgments.-We are grateful to Professor J. M. Thoday, F.R.S., for helpful comments. One of us (B. P. B.) acknowledges the financial support of a Science Research Council Postdoctoral Fellowship and an Agricultural Research Council research grant to Professor Thoday. The analysis was done in part under a General Electric Time-sharing service contract with the University of Maryland.

\section{REFERENGES}

Barnes, B. w. 1968. Stabilising selection in Drosophila melanogaster. Heredity, 23, 433-442. CURNOW, R. N. 1964. The effect of continued selection of phenotypic intermediates on gene frequency. Genet. Res., 5, 341-353.

FALCONER, D. s. 1957. Selection for phenotypic intermediates in Drosophila. 7. Genetics, 55, $551-561$.

GALE, J. S., AND KEARSEY, M. J. 1968. Stable equilibria under stabilising selection in the absence of dominance. Heredity, 23, 553-561.

JAYANT, K. 1966. Birth weight and survival; a hospital survey repeat after 15 years. Ann. Hum. Genet. (Lond.), 29, 367-375.

KARN, M. N., AND PENROSE, L. s. 1951. Birth weight and gestation time in relation to maternal age, parity and infant survival. Ann. Eugen. (Lond.), 16, 147-164.

LATTER, B. D. H. 1960. Natural selection for an intermediate optimum. Aust. 7. Biol. Sci., $13,30-35$.

PRout, T. 1962. The effects of stabilising selection on the time of development in $D$. melanogaster. Genet. Res., 3, 364-382.

REEVE, E. C. R., AND ROBERTSON, F. W. 1953. Analysis of environmental variability in quantitative inheritance. Nature, 171, 874-875. 
RENDEL, J. M. 1943. Variations in the weights of hatched and unhatched duck's eggs. Biometrika, 33, 48-52.

ROBERTSON, A. 1952. The effect of inbreeding on the variation due to recessive genes. Genetics, 37, 189-207.

ROBERTSON, A. 1956. The effect of selection against extreme deviants based on deviation or on homozygosis. F. Genetics, 54, 236-249.

scharLoo, w. 1964. The effect of disruptive and stabilising selection on the expression of a cubitus interruptus mutant in Drosophila. Genetics, 50, 553-562.

SINGH, M., AND LEWONTIN, R. G. 1966. Stable equilibria under optimizing selection. P.N.A.S., 56, 1345-1348.

THODAY, J. M. 1958. Homeostasis in a selection experiment. Heredity, 12, 401-415.

THODAY, J. M. 1959. Effects of disruptive selection. I. Genetic flexibility. Heredity, 13, 187-203.

WRIGHT, SEWALL. 1935. The analysis of variance and the correlations between relatives with respect to deviations from an optimum. 7. Genetics, 30, 243-256. 